\title{
The foundation of the Institute of Paediatric Virology on the island of Euboea, Greece (Review)
}

\author{
IOANNIS N. MAMMAS ${ }^{1-4}$, ANNE GREENOUGH ${ }^{5,6}$, \\ MARIA THEODORIDOU ${ }^{1,4}$ and DEMETRIOS A. SPANDIDOS ${ }^{1,3}$ \\ ${ }^{1}$ Institute of Paediatric Virology; ${ }^{2}$ Paediatric Clinic, Aliveri, 34500 Island of Euboea; \\ ${ }^{3}$ Laboratory of Clinical Virology, Medical School, University of Crete, 71003 Heraklion; \\ ${ }^{4}$ First Department of Paediatrics, University of Athens School of Medicine, 11527 Athens, Greece; \\ ${ }^{5}$ Department of Women and Children's Health, School of Life Course Sciences, \\ Faculty of Life Sciences and Medicine, King's College London, London SE5 9RS; \\ ${ }^{6}$ Asthma UK Centre in Allergic Mechanisms of Asthma, King's College London, London SE1 9RT, UK
}

Received July 31, 2020; Accepted October 24, 2020

DOI: 10.3892/etm.2020.9432

'Every art and every inquiry, and similarly every action and pursuit, is thought to aim at some good; and for this reason the good has rightly been declared to be that at which all things should aim,

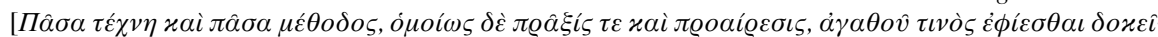

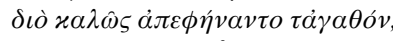
ovं $\left.\pi \alpha ́ v \tau^{\prime} \dot{\varepsilon} \phi i \varepsilon \tau \alpha \iota\right]$

Aristotle

\begin{abstract}
The Institute of Paediatric Virology, founded on October 2019 on the island of Euboea in Greece, introduces medical students, paediatric and neonatal trainees, postgraduate students, virologists, paediatric and allied health professionals to the bold, new, scientific field of paediatric virology. The institute is committed to medical education and is the sequel of the Paediatric Virology Study Group (PVSG), which was formed in 2007 in the United Kingdom by a group of young paediatric trainees and junior researchers. The main mission of the institute is to provide an educational e-platform on neonatal and paediatric viral infections, to facilitate scientific discussion between virologists and paediatric health professionals and to develop an international network aiming to the promotion of children's health by the prevention and treatment of viral infectious diseases. The foundation of the institute is dedicated to three children from a small fishing village at the south of the island of Euboea in Greece, who survived the 1918 Spanish flu pandemic.
\end{abstract}

Correspondence to: Professor Demetrios A. Spandidos, Laboratory of Clinical Virology, Medical School, University of Crete, 71003 Heraklion, Greece

E-mail: spandidos@spandidos.gr

Dr Ioannis N. Mammas, Paediatric Clinic, Aliveri, 34500 Island of Euboea, Greece

E-mail: mammasjo@googlemail.com

Key words: Institute of Paediatric Virology, paediatric virology, medical education, subspecialty

\section{Contents}

1. Introduction

2. The paediatric virology proposal

3. The mission of the institute

4. The subspecialty module

5. The institute's groups and committees

6. Lectures - workshops - awards on paediatric virology

7. Support

\section{Introduction}

In 2007, at the Wirral University Teaching Hospital in Merseyside (UK), a group of young paediatric trainees and junior researchers interested in neonatal and paediatric viral infections created the Paediatric Virology Study Group (PVSG) (1) (Fig. 1). This was inspired by two cytomegalovirus (CMV)-positive twins, who were treated at the local Neonatal Intensive Care Unit (NICU) (2). The management of the twins required the collaboration of an extended scientific network in Merseyside and Manchester (UK), including several experienced consultants in neonatology, paediatrics, paediatric infectious diseases (PID) and microbiology. Since then, PVSG has asked for the support and advice of leading worldwide experts in paediatric virology, including Nobel Laureate Professor of Virology Harald zur Hausen (Heidelberg, Germany), who to date, has been supporting the PVSG with enthusiasm (Fig. 2).

One of the most significant hallmarks in the legacy of the PVSG was the annual 'workshop on paediatric virology'. This workshop took place for the first time on the October 10, 2015 as an official session of the "20th World Congress on Advances 


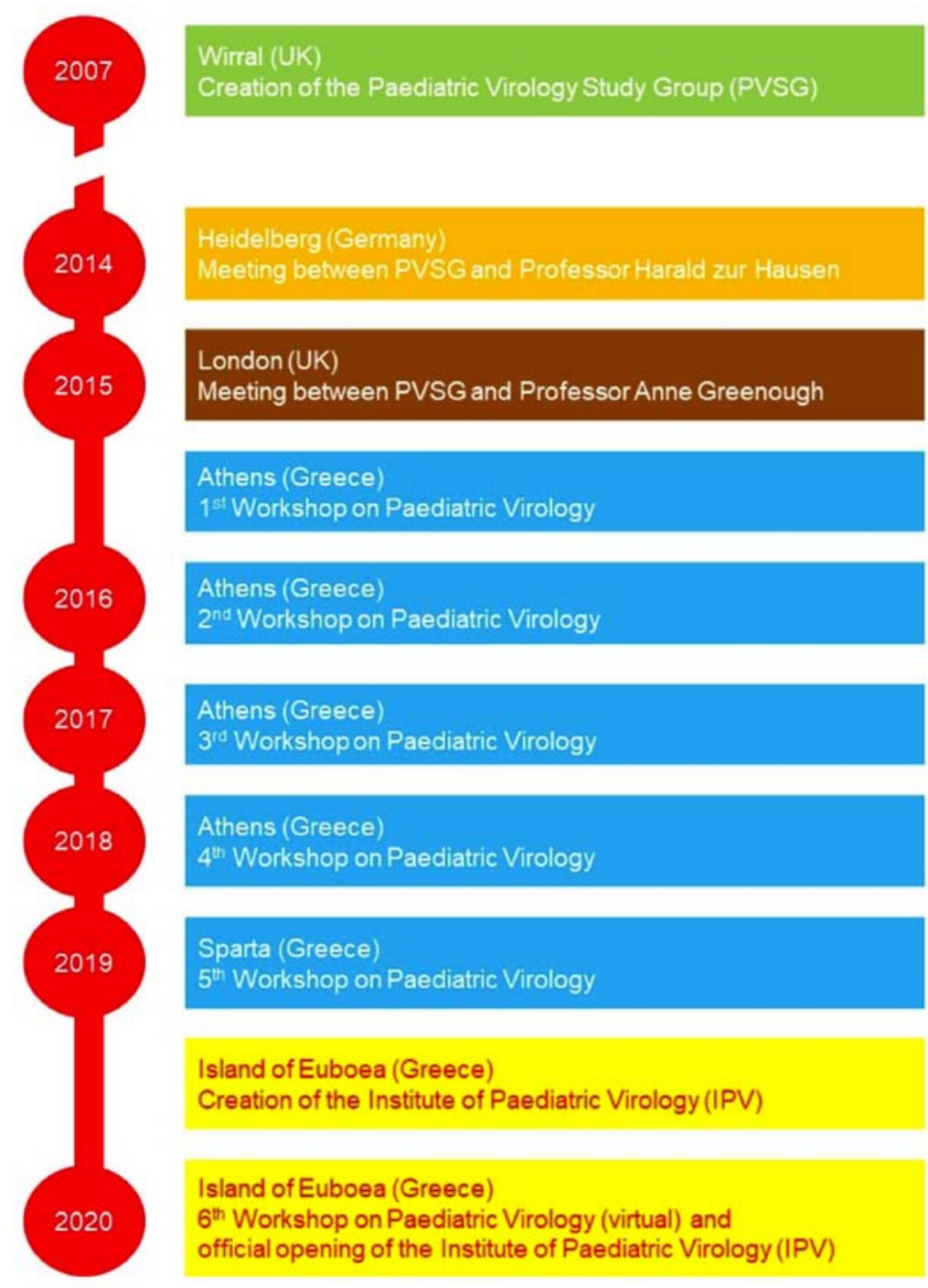

Figure 1. A historical overview: From the creation of the Paediatric Virology Study Group (PVSG) to the official opening of the Institute of Paediatric Virology (IPV) based on the island of Euboea.

in Oncology' and the '18th International Meeting on Molecular Medicine' (3). The PVSG has provided the key points of the presentations from all meetings published in the Experimental and Therapeutic Medicine and the International Journal of Molecular Medicine (3-8). The fundamental aim of these workshops was to bring together virologists with paediatricians and to highlight research and educational activities on viral infections occurring in neonates and children (9).

\section{The paediatric virology proposal}

During the first 'workshop on paediatric virology' in 2015, a detailed proposal of paediatric virology as a separate subspecialty in paediatrics was presented (10). Paediatric trainees were proposed to play a leading role in this new subspecialty, gaining valuable clinical and research experience on the prevention and management of viral infections in neonates and children. Future paediatric virologists have been proposed to play a multi-task role, not only in university-based research and educational settings, but also in primary, secondary and tertiary paediatric services.
This proposal stimulated a very interesting debate, in which several worldwide leading experts in the scientific fields of neonatology, paediatrics, PID and virology participated. These experts were asked by the members of the PVSG to offer their input on the debate of the potential role of paediatric virology as a new paediatric subspecialty (11-13). Although this debate yielded difficulties, challenges and limitations on our proposal, the potential value of paediatric virology subspecialists has undoubtedly been accepted (14) and the '2015 paediatric virology proposal' has been characterized as 'a unique project of paediatric innovation in medical education' (15) and 'an educational goal for advanced academic excellence' (16). This proposal has been also evaluated as 'the base of the initiation of a subspecialty programme on paediatric virology in the near future' (17).

\section{The mission of the institute}

The Institute of Paediatric Virology (IPV) (Fig. 3) was founded in 2019 and is based on the island of Euboea in Greece. Since 2019, the institute's first office is located in Karavos, between 
Dear colleagues,

It is a great pleasure for me to send you this message at the occasion of the official opening of the newly founded Institute of Paediatric Virology based on the island of Euboea in Greece. I greatly support actions of innovation, worldwide, trying to bring together scientists from different countries, backgrounds and levels and encouraging them to collaborate for the common good. The foundation of the Institute of Paediatric Virology is an action of innovation in medicine, trying to bring together paediatricians with virologists and support paediatric health towards virus infections. The primary mission of the institute to highlight the significance of medical education in the rapidly expanding educational field of neonatal and paediatric viral infections is very valuable, indeed. I strongly believe that it is particularly important for young paediatricians to have a good knowledge of the field of virology, of virological methods and diagnostic possibilities. The aim of the institute to create an educational eplatform on paediatric virology will be definitely beneficial.

This institution is the child of the Paediatric Virology Study Group (PVSG), a group of junior paediatricians, who in 2007 started with enthusiasm studying paediatric viral infections and exploring the current weaknesses of modern medicine in this scientific field. When in $2014 \mathrm{I}$ had the chance to meet the group in Heidelberg for the first time, I was impressed by their high scientific standards and ideals.

I also welcome very much the fact that this institute is based on the island of Euboea in Greece, the birth place of the great doctor, scientist and humanitarian Dr George N. Papanicolaou. Here, he was born, received his primary education as a child and spent his summer holidays as a medical student at the University of Athens. Dr George N. Papanicolaou is one of the most extraordinary scientists in modern medical history. We all should pay tribute to his memory and his achievements in medicine. It is my privilege to express our gratitude to him and his excellence. It is a great chance, indeed, to be inspired by his example.

The foundation of the institute is dedicated to three children from the island of Euboea. These children managed to survive the 1918 Spanish flu outbreak despite losing all other members of their families due to this devastating pandemic 102 years ago. Based on this historical memory, tragedy and hope, the newly founded institute is sending to the scientific community the message of the significance of medical education in modem medicine. Almost 2,400 years ago, the value of medical education had been recognized by Hippocrates, 'the Father of Medicine', who in

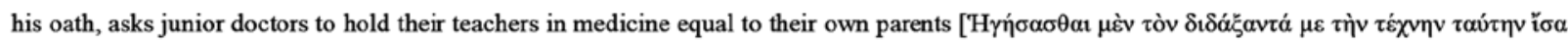

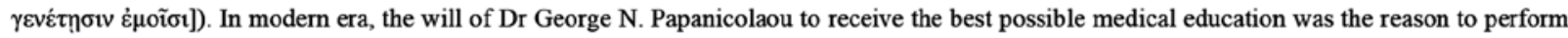
his postgraduate studies in Freiburg in Germany and then move to the US. In his letters to his father, who was also doctor and had proposed to his son a well-predicted and safe medical and political career on his island, Dr George N. Papanicolaou expressed his will to receive the best medical knowledge of his era and to find ways to learn as much as possible and reach at the highest level of knowledge.

The future of medical education is of primary importance, not only in paediatrics, virology and paediatric virology, but for all medical specialties. Medical education needs more inter-national, inter-institutional and multi-scientific collaborations. The difficulties generated by the current health crisis due to SARS-CoV-2 should guide our actions in the coming months and years to more effective global approaches improving state-of-the-art undergraduate, postgraduate and continuous medical education.

All my best wishes for the newly founded Institute of Paediatric Virology based on the island of Euboea in Greece and my best regards from Heidelberg to all of you.

\section{Professor Harald zur Hausen}

Figure 2. Message by Nobel Laureate Professor of Virology Harald zur Hausen on the official opening of the newly founded Institute of Paediatric Virology based on the island of Euboea (Greece).

the customs and port authorities of Aliveri's port and the traditional local fishing village of Karavos (Fig. 4). The foundation of this institute was dedicated to three children from the south of the island of Euboea, who survived of the 1918 Spanish flu outbreak (18-22).

Its aim is to introduce medical students, paediatric and neonatal trainees, postgraduate students, virologists, paediatric and allied health professionals to the scientific field of paediatric virology. The main focus of the institute's activities is to provide an educational e-platform on the current clinical practice and recent research advances on the prevention, diagnosis, management and therapeutics against neonatal and paediatric viral infections. This platform serves as a liaison between virologists and paediatric health professionals aiming to facilitate scientific discussion and encourage collaborative work as an international network to achieve the promotion of paediatric health towards viral infectious diseases. An important aim of the institute's mission is to communicate new knowledge to children' parents and care givers. 


\section{INSTITUTE OF PAEDIATRIC VIROLOGY}

Figure 3. The logo of the Institute of Paediatric Virology (IPV).

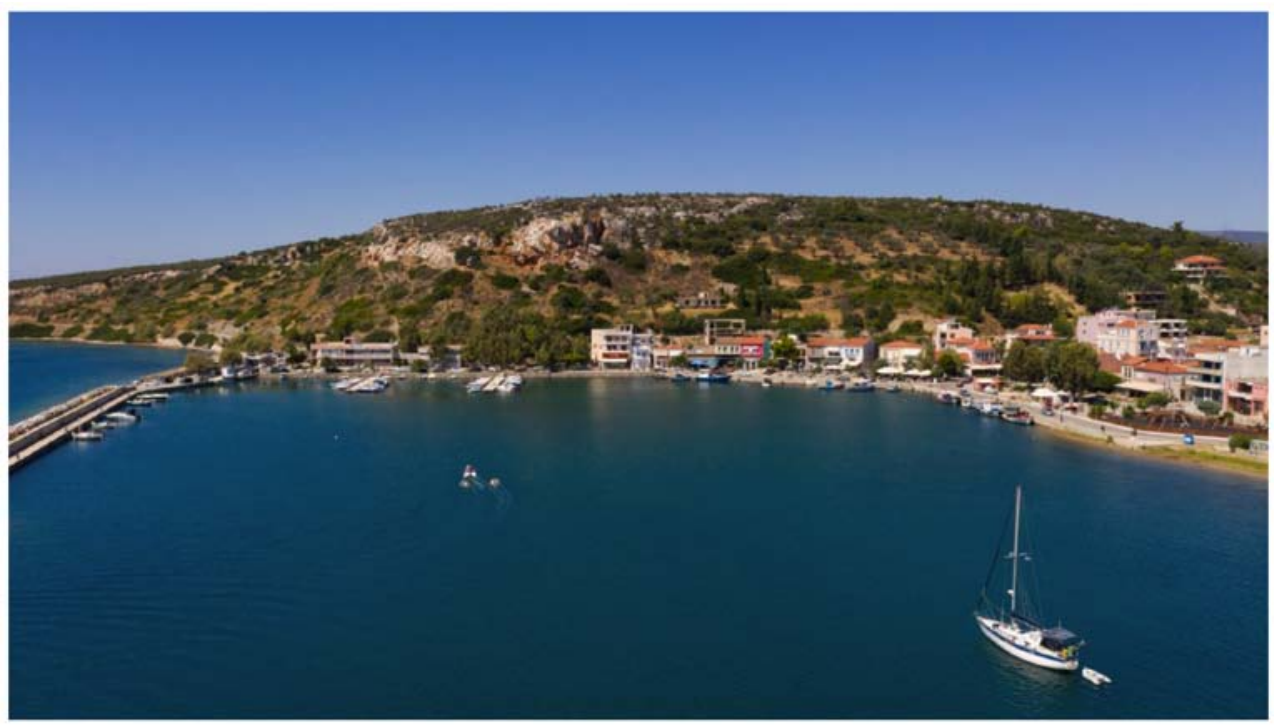

Figure 4. Karavos at Aliveri' seaside on the island of Euboea in Greece. Aliveri is the second biggest city on the island of Euboea and is situated between Chalkida, the island's capital, and Cyme, birth place of Dr George N. Papanicolaou. In 1953, in Aliveri, the first electricity board of Greece was constructed, which, in 2007, was replaced with the Fifth natural gas unit. Recently, archaeological excavations in Karavos revealed one the oldest pre-historic villages in Greece of the early Helladic era, demonstrating that the coastal settlement of Karavos has been inhabited continuously for more than 5,000 years and its habitants had developed significant trading and cultural relations with Attica, the Hellenic mainland and the islands of the Aegean Sea and the Mediterranean Sea reaching as far as Asia Minor, Crete, Cyprus and South Italy (photo by Mr. Christos Stamatas).

The institute is committed to work transparently; therefore, its' news, editions and publications (Table I), annual reports and plans are publicly recorded and accessible free of charge to everyone via the institute's official webpage.

\section{The subspecialty module}

The institute supports that paediatric virology, as a new paediatric subspecialty, can promote neonatal and paediatric health. In the future, paediatric virologists are expected to have a strategic role, both clinically and academically regarding the prevention and treatment of viral infections in infancy and childhood. In this context, the institute is involved in the planning, evaluation and implementation into the clinical practice of a new module of paediatric virology subspecialisation for paediatric trainees and junior health professionals in Greece (Fig. 5). This academic programme will be conducted in collaboration with worldwide state-of-the-art training centers, both clinical and laboratory-based, on neonatal and paediatric viral infections and will be supported by the institute.

\section{The institute's groups and committees}

The structure of the IPV consists of the Paediatric Virology Study Group (PVSG), the Paediatric Virology Council (PVC), the Advisory Academic Board (AAB) and the Scientific Committees (SC), which are responsible for its scientific role and administration.

Paediatric Virology Study Group (PVSG). The PVSG (2) continues to exist having a fundamental role in the structure of the institute. The PVSG is open to scientists interested in the field of paediatric virology, either as students, basic scientists, researchers and virologists, specialty trainees (STs), consultant paediatricians and neonatologists, PID physicians or allied health professionals. 
Table I. Editions and publications (National Center for Biotechnology Information - Accessed on Saturday July 11th, 2020) on paediatric virology by the Paediatric Virology Study Group (PVSG) and the newly founded Institute of Paediatric Virology (IPV).

\section{Editions}

1. 6th Workshop on Paediatric Virology and the Official Opening of the Institute of Paediatric Virology. Institute of Paediatric Virology, Island of Euboea, 2020.

2. COVID-19 pandemic threat in children: discussing with worldwide experts - archives 2. Institute of Paediatric Virology, Island of Euboea, 2020.

3. COVID-19 pandemic threat and frontline medical professionals - archives 1. Institute of Paediatric Virology, Island of Euboea, 2020.

4. The statute. Institute of Paediatric Virology, Island of Euboea, 2019.

5. $\quad$ 5th Workshop on Paediatric Virology. Paediatric Virology Study Group, Sparta, 2019.

6. $\quad$ 4th Workshop on Paediatric Virology. Paediatric Virology Study Group, Athens, 2018.

7. $\quad 3 r d$ Workshop on Paediatric Virology. Paediatric Virology Study Group, Athens, 2017.

8. 2nd Workshop on Paediatric Virology. Paediatric Virology Study Group, Athens, 2016.

9. Workshop on Paediatric Virology. Paediatric Virology Study Group, Athens, 2015.

\section{Publications}

1. Mammas IN, Drysdale SB, Rath B, Theodoridou M, Papaioannou G, Papatheodoropoulou A, Koutsounaki E, Koutsaftiki C, Kozanidou E, Achtsidis V, et al: Update on current views and advances on RSV infection (Review). Int J Mol Med 46: 509-520, 2020.

2. Mammas IN, Greenough A, Theodoridou M and Spandidos DA: Educational pathways in Paediatric Virology: Pros and cons. Exp Ther Med 18: 3260-3262, 2019.

3. Koutsaftiki C, Mammas IN, Papatheodoropoulou A, Koutsounaki E, Theodoridou M and Spandidos DA: Paediatric Virology and the indisputable value of prevention. Exp Ther Med 18: 3257-3259, 2019.

4. Mammas IN and Spandidos DA: Practicing humility and medical education: Lessons learnt interviewing experts on Paediatric Virology. Exp Ther Med 18: 3254-3256, 2019.

5. Mammas IN and Spandidos DA: The value of scientific patience. Exp Ther Med 18: 3252-3253, 2019.

6. Mammas IN, Koutsaftiki C, Papatheodoropoulou A and Spandidos DA: Mache Papanicolaou (1890-1982), the dedicated companion of the great benefactor: An interview with Dr Julie Kokkori, one of the only living relatives of Dr George N. Papanicolaou. Exp Ther Med 18: 3248-3251, 2019.

7. Mammas IN and Spandidos DA: The perspectives and the challenges of Paediatric Radiology: An interview with Dr Georgia Papaioannou, Head of the Paediatric Radiology Department at the 'Mitera' Children's Hospital in Athens, Greece. Exp Ther Med 18: 3238-3242, 2019.

8. Mammas IN and Spandidos DA: Advancing challenges in Paediatric Virology: An interview with Professor Barbara A. Rath, Co-founder and Chair of the Vienna Vaccine Safety Initiative. Exp Ther Med 18: 3231-3237, 2019.

9. Mammas IN and Spandidos DA: Paediatric Virology and respiratory syncytial virus: An interview with Honorary Senior Lecturer in Paediatric Infectious Diseases Dr Simon B. Drysdale (St. George's, University of London, UK). Exp Ther Med 18: 3226-3230, 2019.

10. Spandidos DA: Paediatric Virology and innovation in medical education: An interview with Dr Ioannis N. Mammas, Consultant Paediatrician on the island of Euboea (Greece) and Coordinator of the Paediatric Virology Study Group. Exp Ther Med 18: 3243-3247, 2019.

11. Mammas IN: Clinical Virology research and medical education in Greece: An interview with Demetrios A. Spandidos, Professor of Clinical Virology at the University of Crete in Greece. Exp Ther Med 18: 3221-3225, 2019.

12. Mammas IN, Theodoridou M and Spandidos DA: The wisdom and eudaimonia of Paediatrics: An interview with Professor George P. Chrousos, Professor of Paediatrics and Endocrinology at the University of Athens, Greece. Exp Ther Med 18: 3217-3220, 2019.

13. Chrousos GP, Mammas IN and Spandidos DA: The role of philosophy in medical practice. Exp Ther Med 18: 3215-3216, 2019.

14. Mammas IN, Dalianis T, Doukas SG, Zaravinos A, Achtsidis V, Thiagarajan P, Theodoridou M and Spandidos DA: Paediatric virology and human papillomaviruses: An update. Exp Ther Med 17: 4337-4343, 2019.

15. Mammas IN, Theodoridou M, Thiagarajan P, Melidou A, Papaioannou G, Korovessi P, Koutsaftiki C, Papatheodoropoulou A, Calachanis M, Dalianis T, et al: A paediatric influenza update 100 years after the Skyros island Spanish flu outbreak. Exp Ther Med 17: 4327-4336, 2019. 
Table I. Continued.

Publications

16. Mammas IN and Spandidos DA: Paediatric virology as a candidate of paediatric subspecialisation: An interview with Assistant Professor of Molecular Microbiology-Virology Angeliki Melidou. Exp Ther Med 16: 2795-2798, 2018.

17. Mammas IN and Spandidos DA: The future of medical education in neonatology, paediatrics and paediatric virology: An interview with Professor Alan Michael Weindling, Professor of Perinatal Medicine at the University of Liverpool. Exp Ther Med 16: 2805-2808, 2018.

18. Mammas IN, Spandidos DA and Weindling AM: The future of paediatric education. Exp Ther Med 16: 2803-2804, 2018.

19. Mammas IN and Spandidos DA: The philosophy of paediatric teaching: An interview with Dr Nikolaos Myriokefalitakis, former Clinical Director of the 'Penteli' Children's Hospital in Athens (Greece). Exp Ther Med 16: 2799-2802, 2018.

20. Mammas IN and Spandidos DA: Neonatology, paediatrics and paediatric virology on a British island: An interview with neonatologist Dr Prakash Thiagarajan (Isle of Man). Exp Ther Med 16: 2790-2794, 2018.

21. Mammas IN and Spandidos DA: Evaluating the proposal of paediatric virology: An interview with Professor Tina Dalianis, Professor of Tumour Virology at Karolinska Institutet. Exp Ther Med 16: 2785-2789, 2018.

22. Mammas IN, Greenough A, Theodoridou M and Spandidos DA: Does Europe need paediatric virologists? Exp Ther Med 16: 2783-2784, 2018.

23. Mammas IN, Theodoridou M and Spandidos DA: The 1918 Spanish flu outbreak that devastated a Greek island underlines past lessons that must never be forgotten. Acta Paediatr 107: 2034, 2018.

24. Mammas IN and Spandidos DA: Spinal muscular atrophy type I and the dual role of viruses: An interview with Professor Basil T. Darras, Professor of Neurology (Pediatrics) at Harvard Medical School. Exp Ther Med 15: 3673-3679, 2018.

25. Darras BT, Mammas IN and Spandidos DA: Spinal muscular atrophy, pediatric virology and gene therapy: A challenge of modern weakness and hope. Exp Ther Med 15: 3671-3672, 2018.

26. Mammas IN, Greenough A, Theodoridou M, Kramvis A, Rusan M, Melidou A, Korovessi P, Papaioannou G, Papatheodoropoulou A, Koutsaftiki C, et al: Paediatric Virology and its interaction between basic science and clinical practice (Review). Int J Mol Med 41: 1165-1176, 2018.

27. Mammas IN and Spandidos DA: George N. Papanicolaou (1883-1962), an exceptional human, scientist and academic teacher: An interview with Dr Neda Voutsa-Perdiki. Exp Ther Med 14: 3346-3349, 2017.

28. Mammas IN and Spandidos DA: Viral infections, neonatal mortality and the mystery of the Athenian Agora: An interview with Professor of Anthropology Maria Liston. Exp Ther Med 14: 3341-3345, 2017.

29. Mammas IN and Spandidos DA: The proposal of Paediatric Virology and its perspectives: An interview with Professor of Paediatrics Maria Theodoridou. Exp Ther Med 14: 3338-3340, 2017.

30. Mammas IN and Spandidos DA: The innovation of the subspecialty of Paediatric Virology: An interview with Research Professor of Molecular Virology Anna Kramvis. Exp Ther Med 14: 3335-3337, 2017.

31. Mammas IN and Spandidos DA: The educational challenge of Paediatric Virology: An interview with Professor of Neonatology Anne Greenough. Exp Ther Med 14: 3332-3334, 2017.

32. Mammas IN and Spandidos DA: Paediatric Virology as a new educational initiative: An interview with Nobelist Professor of Virology Harald zur Hausen. Exp Ther Med 14: 3329-3331, 2017.

33. Zur Hausen H, Mammas IN and Spandidos DA: HPV vaccination in boys: Determining the clinical relevance of this strategy. Exp Ther Med 14: 3327-3328, 2017.

34. Mammas IN and Spandidos DA: Athens-based meeting to discuss the paediatric virology crossroad in October 2017. Acta Paediatr 106: 1536, 2017.

35. Mammas IN, Theodoridou M, Kramvis A, Thiagarajan P, Gardner S, Papaioannou G, Melidou A, Koutsaki M, Kostagianni G, Achtsidis V, et al: Paediatric Virology: A rapidly increasing educational challenge. Exp Ther Med 13: 364-377, 2017.

36. Mammas IN, Theodoridou M and Spandidos DA: The development of the Paediatric Virology Study Group: Ten years in the making. Exp Ther Med 13: 363, 2017.

37. Mammas IN and Spandidos DA: Paediatric Virology in the Hippocratic Corpus. Exp Ther Med 12: 541-549, 2016.

38. Mammas IN and Spandidos DA: The subspecialty of Paediatric Virology: A 'mosaic tile' in future Paediatrics. Exp Ther Med 12: 539-540, 2016.

39. Mammas IN, Greenough A, Theodoridou M, Kramvis A, Christaki I, Koutsaftiki C, Koutsaki M, Portaliou DM, Kostagianni G, Panagopoulou P, et al: Current views and advances on Paediatric Virology: An update for paediatric trainees. Exp Ther Med 11: 6-14, 2016.

40. Mammas IN, Greenough A, Theodoridou M and Spandidos DA: Paediatric Virology: A new paediatric subspecialty? A proposal at the Workshop on Paediatric Virology, Athens, October 10, 2015. Exp Ther Med 11: 3-5, 2016. 


\section{Dear colleagues,}

During the last two decades, our diagnostic abilities on and armamentarium against viruses have increased immensely. New diagnostic procedures and novel anti-viral agents, therapeutic monoclonal antibodies, and crucial antiviral vaccines have been developing in a rapid rate. The overall field of paediatric infectious diseases has benefitted greatly from these advances, and paediatric virology - which at this moment is integrated in the paediatric infectious diseases field, along with bacteriology, mycology and parasitology-, can now stand alone. I strongly believe that because of the expected rapid expansion of new knowledge in the field of neonatal and paediatric viral infections in the near future, paediatric virology should be considered an excellent candidate for a new paediatric subspecialisation.

In this direction, the very creative interaction between the National and Kapodistrian University of Athens and the University of Crete Schools of Medicine will be the launching ground for a subspecialty programme in paediatric virology in the near future. The "Institute of Paediatric Virology" will strive to achieve this goal, and its high medical, philosophical and ethical principles will secure a fundamental role in highlighting the value of biomedical education in paediatric viral infections.

With these thoughts, I welcome the newly founded "Institute of Paediatric Virology" based on the island of Euboea, birthplace of the great physician George N. Papanicolaou - the inventor of the pap test that has saved millions of lives. I congratulate the founders and wish them all the best in achieving their highly worthy mission!

\section{George P. Chrousos, MD}

Figure 5. Message by Professor George P. Chrousos (First Department of Paediatrics, University of Athens) on the official opening of the newly founded Institute of Paediatric Virology based on the island of Euboea (Greece).

Paediatric Virology Council (PVC). The PVC is charged with defining the institute's overall scientific directions and priorities. It is elected, supported and advised by the PVSG. The president of the PVC is also elected by the PVSG and is the president (scientific director) of the institute.

Advisory Academic Board (AAB). The AAB of the institute consists of worldwide experts on paediatric virology with strong international reputation and seminal contributions in the field. The chairman of the AAB is proposed by the PVSG and approved by the PVC.

Scientific Committees (SC). The SC of the institute are study working groups, which focus on specific topics of interest in the field of paediatric virology. The chairman of each SC is proposed by the PVSG and is approved by the PVC.

\section{Lectures - workshops - awards on paediatric virology}

The institute maintains a well-regarded and popular lecture series in Greece as well as abroad providing hot topics on paediatric virology by worldwide experts on the field. In addition, its workshops offer the opportunity to post-graduate students and junior researchers in clinical virology and molecular medicine to present their work to the paediatric community.

Each year, the institute honours experts in paediatric virology, paediatrics, neonatology, PID, clinical virology and medical education with a range of specific awards. Special awards, such as the 'George N. Papanicolaou Humanitarian Award', are given to scientists with outstanding achievements in medicine, science and humanity. Awarded individuals are selected by the PVSG based on their achievements and continued dedication to the field of neonatal and peadiatric viral infections and in medicine.

\section{Support}

The institute is under the auspices of the World Academy of Sciences (WAS), which is devoted to academic excellence in sciences. WAS has no political affiliations and does not discriminate on the basis of race, religion, age, sexual orientation, mental or physical disability in any of its activities or operations. The institute is supported by the Department of Clinical Virology at the University of Crete School of Medicine (Heraklion, Greece) and the First Department of Paediatrics at the University of Athens School of Medicine (Athens, Greece).

There are no obligations or fees for the members of the institute as well as for the scientific community and parents, whose access to the institute's e-platform is free of charge. The institute is also independent from any national government, pharmaceutical company, medical society or association or other scientific, political or financial institution. The AAB acts as the institutes' ethics body ensuring the highest standards and conforming to institute's independence, excellence and commitment to transparency.

\section{Acknowledgements}

This article is published in the context of the foundation of the Institute of Paediatric Virology (IPV; https:// paediatricvirology.org) based on the island of Euboea (Greece), under the auspices of the World Academy of Sciences (WAS) 
and the support of the Department of Clinical Virology of the University of Crete School of Medicine and the First Department of Paediatrics of the University of Athens School of Medicine. We would like to thank all the members of the IPV for their valuable comments and corrections.

\section{Funding}

No funding was received.

\section{Availability of data and materials}

Not applicable.

\section{Authors' contributions}

INM, AG, MT and DAS contributed equally to the conception and design of this manuscript, wrote the original draft, edited and critically revised the manuscript, read and approved the final manuscript.

\section{Ethics approval and consent to participate}

Not applicable.

\section{Patient consent for publication}

Not applicable.

\section{Competing interests}

INM, MT and DAS are Co-founders of the Institute of Paediatric Virology (IPV). AG is Chair of the Advisory Academic Board (AAB) of the IPV. DAS is the Editor-in-Chief for the journal, but had no personal involvement in the reviewing process, or any influence in terms of adjudicating on the final decision, for this article.

\section{References}

1. Mammas I, Breen L, Rackham O and Hughes A: Congenital cytomegalovirus (CMV) infection in twins born by a CMV-negative mother. Acta Paediatr 97: 317, 2008.

2. Mammas IN, Theodoridou $M$ and Spandidos DA: The development of the Paediatric Virology Study Group: Ten years in the making. Exp Ther Med 13: 363, 2017.

3. Mammas IN, Greenough A, Theodoridou M, Kramvis A, Christaki I, Koutsaftiki C, Koutsaki M, Portaliou DM, Kostagianni G, Panagopoulou P, et al: Current views and advances on Paediatric Virology: An update for paediatric trainees. Exp Ther Med 11: 6-14, 2016.

4. Mammas IN, Theodoridou M, Kramvis A, Thiagarajan P, Gardner S, Papaioannou G, Melidou A, Koutsaki M, Kostagianni G, Achtsidis V, et al: Paediatric Virology: A rapidly increasing educational challenge. Exp Ther Med 13: 364-377, 2017.

5. Mammas IN, Greenough A, Theodoridou M, Kramvis A, Rusan M, Melidou A, Korovessi P, Papaioannou G, Papatheodoropoulou A, Koutsaftiki C, et al: Paediatric Virology and its interaction between basic science and clinical practice (Review). Int J Mol Med 41: 1165-1176, 2018.
6. Mammas IN, Theodoridou M, Thiagarajan P, Melidou A, Papaioannou G, Korovessi P, Koutsaftiki C, Papatheodoropoulou A, Calachanis M, Dalianis T, et al: A paediatric influenza update 100 years after the Skyros island Spanish flu outbreak. Exp Ther Med 17: 4327-4336, 2019.

7. Mammas IN, Dalianis T, Doukas SG, Zaravinos A, Achtsidis V, Thiagarajan P, Theodoridou M and Spandidos DA: Paediatric virology and human papillomaviruses: An update. Exp Ther Med 17: 4337-4343, 2019.

8. Mammas IN, Drysdale SB, Rath B, Theodoridou M, Papaioannou G, Papatheodoropoulou A, Koutsounaki E, Koutsaftiki C, Kozanidou E, Achtsidis V, et al: Update on current views and advances on RSV infection (Review). Int J Mol Med 46: 509-520, 2020

9. Mammas IN and Spandidos DA: Athens-based meeting to discuss the paediatric virology crossroad in October 2017. Acta Paediatr 106: 1536, 2017.

10. Mammas IN, Greenough A, Theodoridou M and Spandidos DA: Paediatric Virology: A new paediatric subspecialty? A proposal at the Workshop on Paediatric Virology, Athens, October 10, 2015. Exp Ther Med 11: 3-5, 2016.

11. Mammas IN and Spandidos DA: The subspecialty of Paediatric Virology: A 'mosaic tile' in future Paediatrics. Exp Ther Med 12: 539-540, 2016.

12. Mammas IN, Greenough A, Theodoridou M and Spandidos DA: Does Europe need paediatric virologists? Exp Ther Med 16: 2783-2784, 2018.

13. Mammas IN, Greenough A, Theodoridou M and Spandidos DA: Educational pathways in Paediatric Virology: Pros and cons. Exp Ther Med 18: 3260-3262, 2019.

14. Mammas IN and Spandidos DA: Paediatric Virology and respiratory syncytial virus: An interview with Honorary Senior Lecturer in Paediatric Infectious Diseases Dr Simon B. Drysdale (St George's, University of London, UK). Exp Ther Med 18: 3226-3230, 2019.

15. Mammas IN and Spandidos DA: Advancing challenges in Paediatric Virology: An interview with Professor Barbara A. Rath, Co-founder and Chair of the Vienna Vaccine Safety Initiative. Exp Ther Med 18: 3231-3237, 2019.

16. Mammas IN: Clinical Virology research and medical education in Greece: An interview with Professor of Clinical Virology Demetrios A. Spandidos. Exp Ther Med 18: 3221-3225, 2019.

17. Mammas IN, Theodoridou M and Spandidos DA: The wisdom and eudaimonia of Paediatrics: An interview with Professor George P. Chrousos, Professor of Paediatrics and Endocrinology at the University of Athens, Greece. Exp Ther Med 18: 3217-3220, 2019.

18. Spandidos DA: The newly founded Institute of Paediatric Virology and the 1918 flu outbreak: From mnemosyne to scientific truth. Exp Ther Med (In Press).

19. Mammas IN: The influenza in Port Buffalo in the island of Euboea: a family's reference. To Roptro 57: 62-66, 2019 (In Greek).

20. Mammas IN, Theodoridou M and Spandidos DA: The 'Spanish' flu outbreak at the islands of Skyros, Euboea and Andros 100 years ago. Int J Mol Med 42: S22, 2018.

21. Mammas IN: An idea, an aim, an institute devoted to medical education on paediatric virology. Exp Ther Med (In Press).

22. Mammas IN, Theodoridou M and Spandidos DA: The 1918 Spanish flu outbreak that devastated a Greek island underlines past lessons that must never be forgotten. Acta Paediatr 107: 2034, 2018.

This work is licensed under a Creative Commons Attribution-NonCommercial-NoDerivatives 4.0 International (CC BY-NC-ND 4.0) License. 